\title{
Pulmonary hypertension before and after balloon mitral Valvuloplasty
}

\author{
Mandal I \\ ${ }^{1}$ Dr Indrajit Mandal, M.D. (Pediatric Medicine), D.M. (Cardiology), Assistant Professor, Department of Cardiology, \\ N.R.S. Medical College and Hospital, Kolkata, West Bengal, India.
}

Address for Correspondence: Dr Indrajit Mandal, Email: drindumandal@gmail.com

\begin{abstract}
Objective: To testify effectiveness of BMV in mitral stenosis to resolve pulmonary hypertension. Material and Method: The study was conducted at N.R.S Medical College and Hospital over 18 months with 39 patients of severe mitral stenosis with pulmonary hypertension. They were followed up at 48hours, 1 month and 6 month after BMV. Result: $20.51 \%$ patients had mild, $41.02 \%$ patients had moderate and $38.46 \%$ patients had severe pulmonary hypertension before BMV. Mean mitral valve area before and after BMV were $0.89 \pm 0.11 \mathrm{~cm}$ and $1.89 \pm 0.21 \mathrm{~cm}$ respectively. Mean transmitral gradient was $15.43 \pm 2.3 \mathrm{~mm}$ of $\mathrm{Hg}$ before and $7.86 \pm 2.25 \mathrm{~mm}$ of $\mathrm{Hg}$ after BMV. On $3^{\text {rd }}$ day, before discharge PASP became normal in 1 patient in mild group although improvement was not statistically significant $(\mathrm{p}=0.234)$ but statistically significant improvement of PSBP was seen in both moderate and severe groups ( $\mathrm{p}=0.001)$. At $1 \mathrm{~m}$ follow up PASP came down to normal in 3 patients of mild group $(\mathrm{p}=0.106) .5$ of moderate and 1 patient of severe groups also improved to have PSBP $<25 \mathrm{~mm}$ of $\mathrm{Hg}$, the finding was statistically significant in both groups $(\mathrm{p}=0.001)$. The improvement in all three groups at final check up at $6 \mathrm{~m}$ was statistically significant $(\mathrm{p}=0.001) .5$ patients in each mild and moderate and 2 in severe group were found to have normal PASP. Conclusion: In spite of significant risk, BMV is worth doing in patients with pulmonary hypertension due to mitral stenosis as there is not only dramatic relief of PH of cardiac causes but also improvement of PH due to pulmonary pathology to some extent.
\end{abstract}

Key words: Pulmonary hypertension, Balloon mitral valvuloplasty, pulmonary arterial systolic pressure

\section{Introduction}

Pulmonary Hypertension ( $\mathrm{PH})$ is no more an orphan disease. Indeed a number of recent discoveries have improved our understanding of the disease, helped guide patient management. It is a complex and multidisciplinary disorder [1]. PH, a hemodynamic abnormality, occurs in a number of conditions and characterized by increased right ventricular after-load and work [2]. The World Health Organization divides pulmonary hypertension $(\mathrm{PH})$ into five groups, based on the cause of the condition [3]. Type 2 includes pulmonary hypertension due to left heart disease. Left heart valvular disease increases pulmonary hypertension due back pressure. One of the important cause of left heart valvular heart disease is RHD. According to RHD global registry (REMEDY), which is currently ongoing in almost 30 centres in Africa, Middle East and India, incidence of RHD - a chronic heart condition caused

Manuscript received: $2^{\text {nd }}$ March 2017 Reviewed: $10^{\text {th }}$ March 2017

Author Corrected: $17^{\text {th }}$ March 2017

Accepted for Publication: $23^{\text {rd }}$ March 2017 by rheumatic fever -- is much higher in India than what is presently believed. A study conducted by AIIMS in and around Delhi to see prevalence of RHD among children in northern India had found prevalence of 20.4/1000 school children as against 1 per 1000 children earlier believed [4]. Dr K Srinath Reddy, the new president of the World Heart Federation said that though India feels it has managed to control RHD, the prevalence of the disease is still high in states like Uttar Pradesh and Bihar [4]. Socio-economic and environmental factors like poverty, overcrowding, poor housing, under-nutrition and shortage of resources for health care, delayed diagnosis and low-level awareness are responsible for high incidence of rheumatic fever thus rheumatic heart disease in the developing countries [5]. In developing countries, RF accounts for up to $60 \%$ of all cardiovascular disease in children and young adults [6,7]. The order of involvement of valves in RHD was mitral $(60.2 \%)$, followed by aortic, tricuspid and pulmonary valves [8]. RHD mainly affects mitral valve 
and mitral stenosis is a common occurrence. If left untreated sooner or later MS will lead to PH. Although pulmonary hypertension is a life threatening condition but it improves following of correction of causative pathology. Relief of mitral stenosis often reverses the pulmonary hypertension. Two treatment options are available in our Govt. medical college hospital, a tertiary care centre, BMV and open heart valvotomy. $\mathrm{BMV}$ is a minimally invasive procedure and symptoms of mitral valve stenosis typically improve right after a balloon valvuloplasty. So BMV became the best treatment option if condition permits. According to various studies the prediction of outcome following PBMV is multifactorial and based not only on morphological characteristics of the valve but also a number of clinical and procedural variables, including age, functional class, effective balloon dilating area, and the final valve area and lastly the experience of the clinical team [9-12]. Moreover treatment expenses are made affordable by our state govt. by declaring free treatment for all at all govt. hospitals. So there is ample scope to diminish the disease load and human suffering in our vicinity. I have undertaken the study to testify the effectiveness of Balloon Mitral Valvuloplasty in mitral stenosis to resolve the pulmonary hypertension.

\section{Materials and Method}

This Analytical and Longitudinal study was undertaken at NilRatan Sirkar Medical College and Hospital over 1year 6 months, November 2014 to April 2016. Total 39 patients of severe mitral stenosis with varying degree of pulmonary hypertension were included.

The patients were initially attended OPD. They were asked questions related to symptoms, thoroughly examined and investigated after recruitment not only to establish the diagnosis but also to assess grading i,e severity of the mitral stenosis and pulmonary hypertension.

The patients were also assessed for any other valve involvement. The cases were selected considering both clinical and morphological variables.

Statistical Analysis: statistical analysis was done using IBM SPSS Statistics 20. Continuous variables were expressed as mean \pm standard deviation. Results were compared using Non parametric related sample Wilcoxon Signed Rank Test. $\mathrm{P}$ value $<0.05$ was considered significant.

\section{Results and Analysis}

After operation they were followed up at $48 \mathrm{hr}, 1$ months and 6 months. The mean age the patients were $21.97 \pm 5.65 \mathrm{yrs}$. 29 patients were female and 10 of them were male. 27 people came from rural area 12 of them were from urban mostly slum area. 13 patients belonged to socioeconomic background below poverty line, 19 of them were from lower income group and rest 7 persons belonged to middle income group. 7 female patients and 2 male patients had atrial fibrillation. 3 patients had previous surgical valvulotomy and 2 had previous BMV. Mitral stenosis and aortic stenosis were coexistence in 1 patient. The patients were classified according to New York Heart Association [13]. 10 (25.64\%) had grade II heart disease, 9 (23.07\%) of them had grade IV and rest 20 i.e. 51.28\% had grade III heart disease. Mitral valve Morphologic Score in $18(46.15 \%)$ patients was $<8$. It was 10 in $8(20.51 \%)$ patients. $6(15.38 \%)$ patients had MVMS 11 and rest $7(17.94 \%)$ had score 12. Left Ventricular Ejection Fraction was $\geq 55 \%$ in $21(53.84 \%)$ patient, $<55 \%$ in $11(28.2 \%), \leq 35 \%$ in $7(17.94 \%)$ patients. Total 26 patients has associated MR. 11(42.30\%) of them had trivial MR. 13 $(50 \%)$ patients was associated with grade $1 \mathrm{MR}$ and only $2(7.69 \%)$ patients had grade $2 \mathrm{MR}$. Mean mitral valve area before and after BMV were $0.89 \pm 0.11 \mathrm{~cm}$ and $1.89 \pm 0.21 \mathrm{~cm}$ respectively. Mean transmitral gradient before BMV was $15.43 \pm 2.3 \mathrm{~mm}$ of $\mathrm{Hg}$ which came down to $7.86 \pm 2.25 \mathrm{~mm}$ of $\mathrm{Hg}$ after BMV. $8(20.51 \%)$ patients had mild pulmonary hypertension. Moderate hypertension was detected in $16(41.02 \%)$ patients whereas as much as $15(38.46 \%)$ patients had severe pulmonary hypertension. On the day of discharge, echocardiographic findings revealed that there was overall improvement in all three groups. PASP was lowered to become normal in $1(0.39 \%)$ individual of mild PH group, the improvement was not statistically significant $(\mathrm{p}=0.234)$. Statistically significant improvement was seen among 7 (17.94\%) of 16 subjects with moderate PH who showed to have mild PSBP, $\mathrm{p}=0.001)$. Of $15(38.46 \%)$ patient of severe hypertension $10(25.64 \%)$ patients were improved to be allotted to moderate $\mathrm{PH}$ and for the rest 5 patient PASP was also decreased which was statistically significant $(\mathrm{p}=0.001)$. At $1 \mathrm{~m}$ follow up echocardiographic evaluation depicted 3 (7.69\%) cases of mild PH group had normal PASP, $(\mathrm{p}=0.106)$. Among 16 (41.02\%) patients of moderate PH category, 5 (12.82\%) subjects were fortunate enough to have normal PSBP, 9 (23.07\%) patients showed mild PH and only 2 (5.12\%) were still remained in moderate PH group. $(\mathrm{p}=0.001)$. PSBP reverted back to normal in $1(2.56 \%)$ case, became mild in 7 $(17.94 \%)$ patients, moderate in $6(15.38 \%)$ cases of severe PH group. $(\mathrm{p}=0.001)$ Final follow-up at $6 \mathrm{~m} 5(12.82 \%)$ of 
each mild and moderate PH categories while 2 (5.12\%) patients of severe PH group had normal PSBP. 10 (25.64\%) cases of each moderate and severe groups improved to have mild $\mathrm{PH}$. The improvement was statistically significant, $(\mathrm{p}=<0.05)$. $2(5.12 \%)$ patients of mild group, $1(2.56 \%)$ case of each moderate and severe group were not improved much. Those who did not improved had associated pulmonary causes of PH.

Table 1: demographic profile of the patients $(n=39)$.

\begin{tabular}{|c|c|c|c|c|c|c|}
\hline \multirow{2}{*}{ Mean age (yrs) } & \multicolumn{2}{|c|}{$\begin{array}{c}\text { Male /Female } \\
\text { Ratio 1:2.9 }\end{array}$} & \multicolumn{2}{c|}{ Rural / Urban variation } & \multicolumn{2}{c|}{ Socio-economic background } \\
\cline { 3 - 7 } & \multicolumn{2}{|c|}{} & \multicolumn{2}{|c|}{ BPL } & $\mathbf{1 3}$ \\
\hline $21.97 \pm 5.65 y \mathrm{yrs}$ & Male & 10 & Rural & 27 & Lower S/E & 19 \\
\cline { 2 - 7 } & Female & 29 & Urban & 12 & Middle class & 07 \\
\hline
\end{tabular}

Table-2: distribution of patients according to NYHA grading, MVMS, LVEF and Associated MR.

\begin{tabular}{|c|c|c|c|c|c|c|c|}
\hline \multicolumn{2}{|c|}{$\begin{array}{c}\text { NYHA Grading of } \\
\text { heart disease }\end{array}$} & \multicolumn{2}{|c|}{$\begin{array}{c}\text { Mitral valve Morphologic } \\
\text { Score (MVMS) }\end{array}$} & \multicolumn{2}{|c|}{$\begin{array}{c}\text { Left Ventricular Ejection } \\
\text { Fraction (LVEF) }\end{array}$} & \multicolumn{2}{|c|}{ Associated MR $(n=26)$} \\
\hline II & $10(25.64 \%)$ & $<8$ & $18(46.15 \%)$ & $\geq 55 \%$ & $21(53.84 \%)$ & Trivial & $11(42.3 \%)$ \\
\hline III & $20(51.28 \%)$ & 10 & $12(20.51 \%)$ & $<55 \%$ & $11(28.2 \%)$ & Grade1 & $13(50 \%)$ \\
\hline \multirow[t]{2}{*}{ IV } & \multirow[t]{2}{*}{$09(23.07 \%)$} & 11 & $05(15.38 \%)$ & \multirow[t]{2}{*}{$\leq 35 \%$} & \multirow[t]{2}{*}{$07(17.94 \%)$} & \multirow[t]{2}{*}{ Grade2 } & \multirow[t]{2}{*}{$02(7.69 \%)$} \\
\hline & & 12 & $04(17.94 \%)$ & & & & \\
\hline
\end{tabular}

Table-3: mitral valve area and transmitral gradient before and after BMV.

\begin{tabular}{|c|c|c|c|}
\hline \multicolumn{2}{|c|}{ Mitral valve area } & \multicolumn{2}{c|}{ Transmitral gradient } \\
\hline Before BMV & After BMV & Before BMV & After BMV \\
\hline Mean & Mean & Mean & Mean \\
$0.89 \pm 0.11 \mathrm{~cm}$ & $1.89 \pm 0.21 \mathrm{~cm}$ & $15.43 \pm 2.3$ & $7.86 \pm 2.25$ \\
\hline
\end{tabular}

Table-4: severity of pulmonary hypertension before and $48 \mathrm{hrs}$, 1month, 6months after BMV.

\begin{tabular}{|c|c|c|c|c|c|c|c|c|c|c|c|c|}
\hline \multicolumn{4}{|c|}{ PH before BMV } & \multicolumn{3}{c|}{ PH 48 after BMV } & \multicolumn{2}{c|}{ PH 1month after BMV } & \multicolumn{3}{c|}{ PH 6months after BMV } \\
\hline SN & Mild & Mod & Sev & Mild & Mod & Sev & Mild & Mod & Sev & Mild & Mod & Sev \\
\hline 1 & 27 & 42 & 56 & 26 & 29 & 53 & 26 & 35 & 44 & 37 & 29 & 38 \\
\hline 2 & 29 & 41 & 57 & 27 & 31 & 54 & 29 & 33 & 39 & 29 & 31 & 39 \\
\hline 3 & 35 & 51 & 59 & 32 & 48 & 56 & 37 & 29 & 49 & 26 & 26 & 49 \\
\hline 4 & 32 & 50 & 56 & 38 & 43 & 52 & 36 & 34 & 43 & & 30 & 35 \\
\hline 5 & 26 & 43 & 58 & 39 & 39 & 54 & 27 & 32 & 49 & & 29 & 39 \\
\hline 6 & 39 & 42 & 59 & 26 & 28 & 57 & & 32 & 38 & & 29 & 38 \\
\hline 7 & 27 & 49 & 56 & 28 & 44 & 52 & & 38 & 49 & & 35 & 39 \\
\hline 8 & 31 & 45 & 58 & & 42 & 54 & & 49 & 39 & & 47 & 39 \\
\hline 9 & & 47 & 56 & & 42 & 52 & & 46 & 34 & & 33 & 29 \\
\hline 10 & & 41 & 56 & & 38 & 51 & & 39 & 34 & & 32 & 47 \\
\hline 11 & & 43 & 57 & & 30 & 55 & & 37 & 52 & & 34 & 39 \\
\hline 12 & & 42 & 59 & & 30 & 57 & & & 39 & & & 41 \\
\hline 13 & & 49 & 56 & & 49 & 54 & & & 43 & & & 56 \\
\hline 14 & & 53 & 59 & & 51 & 57 & & & 56 & & & \\
\hline 15 & & 53 & 58 & & 48 & 58 & & & & & & \\
\hline 16 & & 50 & & & 48 & & & & & & \\
\hline
\end{tabular}




\section{Mild}

\begin{tabular}{|c|c|c|c|c|}
\hline \multicolumn{5}{|c|}{ Statistics $^{\mathbf{a}}$} \\
\hline & Pre_OP & OP_48 & OP_1m & OP_6m \\
\hline Mean & 30.7500 & 30.0000 & 28.0000 & 26.0000 \\
\hline Median & 30.0000 & 27.5000 & 26.5000 & 24.0000 \\
\hline Std. Deviation & 4.49603 & 5.73212 & 5.70714 & 4.95696 \\
\hline Minimum & 26.00 & 24.00 & 22.00 & 22.00 \\
\hline Maximum & 39.00 & 39.00 & 37.00 & 37.00 \\
Std error mean & 1.590 & 2.027 & 2.018 & 1.753 \\
\hline
\end{tabular}

\section{Moderate}

\begin{tabular}{|c|c|c|c|c|}
\hline \multicolumn{5}{|c|}{ Statistics $^{\mathbf{a}}$} \\
\hline & Pre_OP & OP_48 & OP_1m & OP_6m \\
\hline Mean & 46.3125 & 40.0000 & 32.3750 & 29.2500 \\
\hline Median & 46.0000 & 42.0000 & 32.5000 & 29.0000 \\
\hline Std. Deviation & 4.39270 & 8.07465 & 8.33367 & 6.47560 \\
\hline Minimum & 41.00 & 28.00 & 22.00 & 22.00 \\
\hline Maximum & 53.00 & 51.00 & 49.00 & 47.00 \\
Std error mean & 1.098 & 2.019 & 2.083 & 1.619 \\
\hline
\end{tabular}

\section{Severe}

\begin{tabular}{|c|c|c|c|c|}
\hline \multicolumn{5}{|c|}{ Statistics $^{\mathbf{a}}$} \\
\hline & Pre_OP & OP_48 & OP_1m & OP_6m \\
\hline Mean & 57.3333 & 54.4000 & 42.1333 & 38.4000 \\
\hline Median & 57.0000 & 54.0000 & 43.0000 & 39.0000 \\
\hline Std. Deviation & 1.29099 & 2.19740 & 8.21033 & 8.53397 \\
\hline Minimum & 56.00 & 51.00 & 24.00 & 24.00 \\
\hline Maximum & 59.00 & 58.00 & 56.00 & 56.00 \\
Std error mean & 0.333 & 0.567 & 2.120 & 2.203 \\
\hline
\end{tabular}

\section{Discussion}

The study reflected a significant improvement of pulmonary hypertension following BMV. Umesan et al in their study observed a sustained fall in pulmonary pressure at follow up [14]. Pulmonary pressures fall soon after relief of the MS due to fall of left atrial pressure and because elevated pulmonary vascular resistance is usually due to reactive vasoconstriction as opposed to permanent histopathologic changes [15-16]. Funjan MM et al also observed in their study that BMV is an effective procedure in patients with MS and reactive pulmonary hypertension [17]. Mohamed Eid Fawzy in his study reported that immediately following valvotomy, the PASP normalized in one group and in other groups, pulmonary hypertension decreased slightly with further substantial regression occurring overtime. Severe pulmonary hypertension normalized over 6-12 months in patients with successful PMBV [18-21]. When we scrutinized minutely pulmonary causes were found out in those patients who did not improve following BMV.

\section{Conclusion}

Although Balloon Mitral Valvuloplasty for mitral stenosis is associated with significant risk in presence 
Pulmonary hypertension but it is worth doing BMV as it improves dramatically the pulmonary hypertension secondary to heart pathology and also to some extent pulmonary hypertension due pulmonary pathology.

\author{
Abbreviation \\ BMV- Balloon Mitral Valvuloplasty \\ BPL - Below Poverty Line \\ LVEF- Left Ventricular Ejection Fraction \\ MR- Mitral Regurgitation \\ Mod - Moderate \\ MS - Mitral Stenosis
}

MVMS- Mitral Valve Morphologic Score

NYHA- New York Heart Association

PH- Pulmonary Hypertension

PASP- Pulmonary Arterial Systolic Pressure

S/E- Socio-economic condition

Sev-Severe

\section{Funding: Nil, Conflict of interest: None Permission of IRB: Yes}

\section{References}

1. Vallerie V, McLaughlin and Marc Humbert. Pulmonary Hypertension. BRAUNWALD'S HEART DISEASE. $10^{\text {th }}$ Ed. Elsevier Saunders;2015. 1682-1755.

2. Barst RJ, Rubin LJ. Pulmonary Hypertension. HURST'S THE HEART. 13 ${ }^{\text {th }}$ Ed. McGrow Hill 2011. 71: 1609-1633.

3. Simonneau G, Gatzoulis MA, Adatia I, Celermajer D, Denton C, Ghofrani A, Gomez Sanchez MA, Krishna Kumar R, Landzberg M, Machado RF, Olschewski H, Robbins IM, Souza R. Updated clinical classification of pulmonary hypertension. J Am Coll Cardiol. 2013 Dec 24; 62 (25Suppl): D34-41. doi: 10.1016/j.jacc.2013. 10.029 .

\section{Sinha| K, TNN | Apr 23, 2012,}

5. Rheumatic fever and rheumatic heart disease : report of a WHO Expert Consultation, Geneva, 29 October- 1 November 2001.

6. Githang'a D. Rheumatic heart disease. East Afr Med J. 1999 Nov;76(11):599-600.
7. Joint WHO/ISFC meeting on RF/RHD control with emphasis on primary prevention, Geneva, 7-9 September 1994. Geneva, World Health Organization, 1994 (document WHO/CVD 94.1).

8. Manjunath C.N., Srinivas P, Ravindranath K.S., and Dhanalakshmi C. Incidence and patterns of valvular heart disease in a tertiary care high-volume cardiac center: A single center experience. Indian Heart J. 2014 May; 66(3): 320-326.

9. Iung B, Cormier B, Ducimetiére $\mathrm{P}$, et al. Immediate results of percutaneous mitral commissurotomy. A predictive model on a series of 1514 patients. Circulation 1996;94:2124-30.

10. Iung B, Cormier B, Ducimetiére P, et al. Functional results 5 years after successful percutaneous mitral commissurotomy in a series of 528 patients and analysis of predictive factors. J Am Coll Cardiol 1996; 27: 407-14.

11. Hildick-Smith DJR, Taylor GJ, Shapiro LM. Inoue balloon mitral valvuloplasty: long-term clinical and echocardiographic follow-up of a predominantly unfavourable population. Eur Heart J 2000;21:1690-7. [PubMed]

12. Prendergast BD, Shaw TR, Iung B, Vahanian A, Northridge DB. Contemporary criteria for the selection of patients for percutaneous balloon mitral valvuloplasty. Heart. 2002 May;87(5):401-4.

13. The Criteria Committee of New York Heart Association.(1994). Nomenclature and Criteria for diagnosis of Diseases of the Heart and Great Vessels. ( $9^{\text {th }}$ Ed.). Boston: Little Brown \& Co. pp. 253-256.

14. Umesan CV, Kapoor A, Sinha N, Kumar MS, Goel PK. Effect of balloon mitral valvotomy on severe pulmonary arterial hypertension in 315 patients with rheumatic mitral stenosis: Immediate and long term results. J Heart Valve Dis 2000 sep; 9(5): 609-15.

15. Dalen JE, Matloff JM, Evans GL, Hoppin FG Jr, Bhardwaj P, Harken DE, Dexter L. Early reduction of pulmonary vascular resistance after mitral-valve replacement. N Engl J Med. 1967; 277: 387-394.

16. Carabello BA. Modern management of mitral stenosis. Circulation. 2005 Jul 19;112(3):432-7. 


\section{Original Research Article}

17. Funjan MM, Msayer $\mathrm{K} \mathrm{H}$, Taha $\mathrm{Z}$ M. Hemodynamic factors determining immediate response of left atrial pressure reduction attributed to balloon mitral valvotomy. Journal of Al-Nahrain University September 2010; Vol.13 (3):88-98.

18. John S, Bashi VV, Jairaj PS, Muralidharan S, Ravikumar E, Rajarajeswari T, Krishnaswami S, Sukumar IP, Rao PS. Closed mitral valvotomy: early results and long-term follow-up of 3724 consecutive patients. Circulation. 1983 Nov;68(5):891-6.

19. Fawzy ME, Hassan W, Stefadouros M, Moursi M, El Shaer F, Chaudhary MA. Prevalence and fate of severe pulmonary hypertension in 559 patients with severe mitral stenosis undergoing mitral balloon valvotomy. J Heart Valve Dis 2004;13:942-8.

20. Dev V, Shrivastava S. Time course of changes in pulmonary vascular resistance and mechanism of regression of pulmonary artery hypertension after balloon valvotomy. Am J Cardiol 1991;67:439-42.

21. Mohamed Eid Fawzy. Mitral balloon valvotomy, long-term results, its impact on severe pulmonary hypertension, tricuspid regurgitation, atrial fibrillation, left atrial size, left ventricular function. The Egyptian Heart J 2014 june; 66 (2):133-138. Doi :10. 1016/j.ehj.201.

\section{How to cite this article?}

Mandal I. Pulmonary hypertension before and after balloon mitral Valvuloplasty. Int J Med Res Rev 2017;5(03):279-284 doi:10.17511/ijmrr. 2017.i03.11. 